\title{
The Study on Migration and Poverty Alleviation Planning of Daning County
}

\author{
Yanyun Wei, Aiguo Zhang \\ School of Geographical Sciences, Shanxi Normal University, Daning, China \\ Email: 1617199662@qq.com
}

Received 29 March 2016; accepted 23 April 2016; published 26 April 2016

Copyright (C) 2016 by authors and Scientific Research Publishing Inc.

This work is licensed under the Creative Commons Attribution International License (CC BY). http://creativecommons.org/licenses/by/4.0/

c) (i) Open Access

\section{Abstract}

In order to promote the economic development of Daning County and guarantee the people's livelihood, this paper made an overall analysis on progress of migration and poverty alleviation in the past five years. At the same time, considering the existing problems, the paper made a plan to advance migration and poverty alleviation of the next few years and provided a reference for the migration and poverty alleviation work of Daning County in the Thirteenth Five-Year Plan period. This paper selected the relocated families as the research object, interviewed and surveyed six administrative villages under the migration and poverty alleviation policy, and collected relevant information and data. Besides, the authors read a lot of literatures and used many analysis methods such as field investigation, literature analysis, case analysis and reference contrast to study the advances, benefits, existing problems and choke points of migration and poverty alleviation work in Daning County. Finally, the paper made a brief plan on the migration and poverty alleviation work in Daning County of the next few years.

\section{Keywords}

Daning County, Poverty Alleviation by Migration, Planning

\section{Research Background}

In recent years, with the improvement of China's comprehensive national strength, the government has paid much more attention to the issues of "agriculture, rural areas and farmers". And the key to solving the livelihood of the people in rural areas is to make progress on poverty alleviation. The previous local poverty alleviation is of high cost and poor efficiency. Based on the theory of exploration in different places, poverty alleviation by migration is a new way of reducing poverty and it has become a new entry point for poverty alleviation. After several years of efforts, China has made remarkable achievements in the work of poverty alleviation. Firstly, the 
population of poverty gained a substantial reduction and the living conditions in poor areas improved significantly. Secondly, the ecological environment has been restored. Thirdly, the overall progress of social undertakings such as the conditions of running schools in poor areas and medical and health conditions have been significantly improved. A large number of agricultural technologies have been promoted, so the scientific farming level of farmers has been significantly improved [1]. However, the poverty alleviation work in the last few years has encountered some new situations and problems: Poverty rate tends to slow; per capita input cost of poverty alleviation tends to increase; the rate of regional economic contribution is relatively low and the rate of poverty-returning increased. The transition from extensive poverty alleviation pattern to precise pattern caused a heated social discussion, regarding the strategies, mechanism and pattern issues of poverty alleviation. The practical exploration and theoretical research on the poverty alleviation come into being under this background. Migration and poverty alleviation involve many disciplines such as demography, economics, sociology, geography, ethnology, science of religion, etc, and it is a result of comprehensive multi-disciplinary research [2]. In China, Daning County of Shanxi Province is one of the representatives of Lvliang Mountain where many contiguous areas are in poverty situation with special difficulties. In recent years, although the economy has maintained a growth trend, the growth rate is slow and lower than the average growth rate of Linfen city. Per capital GDP of Daning County also ranks the last in the whole county. In addition, the gap between the rich and the poor is too large, and there are too many poor people. Therefore, effective implementation of poverty alleviation is imperative, and the development of poverty alleviation programs in the next few years is particularly important. Using comprehensive methods such as literature analysis, field investigation, case analysis and reference contrast, this study made a plan on the schemes of the migration and poverty alleviation work of Daning County in the Thirteenth Five-Year Plan period, to effectively improve the county's rural living environment, pull down the gap between the rich and the poor, realize the integration of urban and rural, optimize the industrial structure, and maintain the ecological balance. This study is intended to provide a reference for the effective implementation of the county's poverty alleviation.

\section{The General Situation of the Research Area}

Daning County is located in the south of Luliang Mountain and west of Linfen City in Shanxi Province. Pu County and Xi County are to the east of Daning County, and the west of Daning County is the Yanchang County which is on the opposite side of Yellow River; the north of Daning County borders Yonghe County, and the south is adjacent to Ji County. The total area of Daning County is 975 square kilometers and its total population is 80,000 (2014). Ravines spread all over Daning county, which has complex physiognomy, rugged terrain, and only a few Wall Districts. The local climate belongs to the category of warm, temperate, semi-arid continental climate. The winter is cold. In summer, the daytime of the South is longer than that of North. Concentrated rainfall and lots of weather disasters lead to frequent droughts that prevail in Daning County almost every year. The temperature difference between day and night results in harsh natural conditions [3].

Daning County consists of two towns and four townships: Xinshui Township, Qu'e Town, Sanduo Township, Taide Township, Xujiaduo Township and Taigu Township. The total area of arable land is 151.5 thousand Mu. The main food crops are wheat and corn, while cotton and oil are the main economic crops. The main industrial products are raw coal, coke, cement, monosodium glutamate, etc. In addition, there are machinery, hardware, construction, printing, processing and other industries in this county.

\section{The Overall Analysis on Migration and Poverty Alleviation in Daning County}

\subsection{The Progress of Migration Poverty Alleviation}

In recent years, plans on the migration and poverty alleviation of Daning County have been mainly carried out in Taigu Village, which is located on the shore of the Yellow River at the southwest of the county. With a total area of 185 square kilometers, Taigu Township charges over seven administrative villages and 25 natural villages. The total population of Taigu is 4496 , but more than $85 \%$ of the able-bodied labor-force are out for work. The left rural population is basically the elderly people. In order to ensure the living conditions such as "enough food and clothes, habitable house, and convenient transportation" for the villagers, the county government decided to gather the scattered villagers to live in the Township government. From the beginning of 2013 to the end of 2014, 130 families consisting 480 people have resettled through the migration project, of which there are 
58 families with the 7900 yuan average annual income, 72 families under 7900 yuan. Among them, the number of ages ranging from under 16 and to above 60 is 301, which makes up the majority of the total number, and the number of ages ranging from 16 to 60 is only 179.

\subsection{Benefits of Migration and Poverty Alleviation}

Through recent two years' work of poverty alleviation, Taigu Township has achieved benefits in economic, ecological and social aspects. This paper further analyzed the benefits of migration and poverty alleviation by comparing Daing County with its neighboring county Yonghe County (with similar poverty degree, natural and economic conditions to Daning County before poverty alleviation).

\subsubsection{Benefits of Poverty Alleviation}

This study selected the per capita net income (before and after), the degree of poverty, the population of poverty before migration, the population out of poverty after migration, the poverty alleviation rate as indicators to assess the benefits of poverty alleviation, among which, the degree of poverty and the poverty alleviation rate are very important indicators of measuring the effect of immigrant poverty alleviation. The degree of poverty alleviation is the degree of one area's poverty alleviation, and it refers to the increasing range when per capita net income is compared with the poverty line. After the implementation of poverty alleviation policy for some time, the poverty alleviation rate means the rate that per capita net income of the population beyond the proportion of the total population (Table 1 and Table 2).

\subsubsection{Economic Benefits}

Economic benefit refers to the contrast relation between labor expenditure and achievements, namely the relation between input and output [4]. The economic benefit of alleviating poverty by migration refers to the economic benefit brought by migration and relocation for the poor. And the key of migration is to help the poor people get rid of poverty; therefore the economic benefit is another critical point to measure the effects of migration [5]. Based on the statistical data from field research on alleviating poverty by migration in Taigu Village, Daning County, this study has compared the economic benefit discrepancies between relocation within the village and out of the village from several indexes including the per household annual revenue and expenditure as well as their constitution, the growth in revenue and expenditure, the revenue proportion of each industry before and after the relocation (Table 3 and Table 4).

\subsubsection{Ecological Benefits}

Ecological benefit refers to the whole effects which are beneficial to human beings within the ecological system and its range of influence. The ecological benefit of migration in Loess Plateau area is mainly presented by the

Table 1. Contrast between Daning County and Taigu township.

\begin{tabular}{ccc}
\hline Before and after contrast & Before migration & After migration \\
\hline The per capita net income (yuan/year) & 1519.79 & 3608.13 \\
The degree of poverty alleviation & 1.34 & 1.59 \\
Population in poverty (number of people) & 720 & 720 \\
Population out of poverty (number of people) & 115 & 421 \\
The poverty alleviation rate & 0.16 & 0.58 \\
\hline
\end{tabular}

Table 2. Contrast between Daning County and Yonghe county.

\begin{tabular}{ccc} 
Contrast item & Daning County & Yonghe Couny \\
\hline The per capita net income after migration (yuan/year) & 3608.13 & 3115.71 \\
The degree of poverty alleviation after migration & 1.59 & 421 \\
Population out of poverty (number of people) & 0.58 & 380 \\
The poverty alleviation rate after migration & 0.53 \\
\hline
\end{tabular}


Table 3. The contrast of per household annual revenue and expenditure before and after the migration (yuan).

\begin{tabular}{cccc}
\hline \multicolumn{2}{c}{ Per household annual revenue } & \multicolumn{2}{c}{ Per household annual expenditure } \\
\hline Before the relocation & 18139.07 & Before the relocation & 16014.69 \\
After the relocation & 36841.08 & After the relocation & 25739.84 \\
Growth & 18702.01 & growth & 9725.15 \\
\hline
\end{tabular}

Table 4. The contrast of revenue proportion of each industry before and after the migration (\%).

\begin{tabular}{|c|c|c|c|c|}
\hline \multirow{2}{*}{ Contrast item } & \multicolumn{3}{|c|}{ Agriculture } & \multirow{2}{*}{ Non-agriculture } \\
\hline & Grain crop & Fruits & Breeding & \\
\hline Before the relocation & 26.90 & 27.45 & 26.91 & 18.74 \\
\hline After the relocation & 9.00 & 25.75 & 27.65 & 37.6 \\
\hline
\end{tabular}

ecosystem service enhanced by vegetation restoration as well as soil and water conservation after the implementation of migration project [6]. Since ecological environment is a complex synthesis involving weather, climate, vegetation, soil and hydrology, the evaluation of ecological benefit must cover multiple indexes from multiple aspects. As the migration in Taigu Village has not been long, the ecological benefits are not so remarkable that the traditional evaluation data cannot be obtained. Combing the collected material and field research data, the author has finally chosen several indexes, such as the recovery of vegetation in area of origin, the utilization of old houses' bases and cultivated land as well as the utilization ratio of new energy, to evaluate the ecological benefits of migration (Table 5).

\subsubsection{Social Benefits}

The social benefits of migration refer to the social development in both areas of origin and areas of destination, which is promoted by the migration project. Eleven indexes from three aspects comprising education, medical as well as infrastructure and public service have been chosen to measure the after-migration social benefits of research case places of migration project in Taigu Village, Daning County (Table 6).

\subsection{The Existing Problems and Choke Points}

(1) Fund Issues. On one hand, the local fiscal revenue is limited and the State investment is not large, leading to the strain of poverty alleviation funds; on the other hand, the implementation of the poverty alleviation funds is not in place and the intermediaries are too jumbled, resulting in insufficient funds gained by migrants.

(2) Policy Issues. Policy issues are related to three aspects. The first one is migrant fund subsidy. The relocation policy is conducted by an unified standard without considering the different circumstances of farmers, the government implements the subsidy in the same standard, resulting in the unreasonable fund allocation. The second aspect is migrant housing resettlement. The related staff ignored a series of necessary procedures, such as visiting every village household to make a survey, publicize and file, examining and inspecting, etc., which results in more than one residence per household, "migratory-bird" residences. The third aspect is the lack of follow-up support policies after migration. Parts of the migrants return to where they came from, because most migrants are from the remote mountainous areas, with conservative ideas, less education, out-dated labor skills, poor ability to earn a living in the city, and government assistance is restricted to subsidies, which leads to a low standard. And the government has no relative skill training and guidance, so they return to where they came from again.

(3) Public Security Issues. Because the original residents cannot accept the living habits of the migration population and the competition for public infrastructure and service facilities, or migrants can't adapt to the new environment, public security disputes often take place.

(4) Environment Issues. In migrant areas, the environmental pollution and resource shortage lead to the overlarge carrying capacity of local environment. At the same time, the ecological restoration has not been implemented, so some lands are becoming uncultivated ones.

(5) Land issues. Land resettlement issues involve two aspects, one is the issue of land ownership transfer, including how to deal with homesteads after farmers migrate and how to transfer the land contract-management 
Table 5. The contrast of after-migration ecological benefits in Daning County and Yonghe County.

\begin{tabular}{ccc}
\hline Ecological benefits indexes & Daning & Yonghe \\
\hline The percentage of migration places where the field and vegetation condition in area of origin are getting better & 65 & 25 \\
The percentage of old houses whose bases are used to plant trees and grass & 67.25 & 29.75 \\
The after-migration utilization ratio of environment-friendly energy such as solar energy and marsh gas & 37.40 & 21.00 \\
\hline
\end{tabular}

Table 6. The contrast of Daning County's social benefits before and after the migration.

\begin{tabular}{|c|c|c|c|}
\hline Primary indexes & Secondary indexes & Before the migration & After the migration \\
\hline \multirow{5}{*}{ Education } & $\begin{array}{l}\text { enrollment rate of school-age } \\
\text { children of migrants }\end{array}$ & $90.1 \%$ & $97.8 \%$ \\
\hline & distribution of schools & $29.7 \%$ villages have schools & $67.7 \%$ new villages have schools \\
\hline & Distance and time for school & $1 \mathrm{~km} \mathrm{-} 10$ km, 40 minutes - 1 hour & $\begin{array}{c}500 \mathrm{~m} \text { - } 2 \text { km, } 10 \text { minutes - } 30 \\
\text { minutes }\end{array}$ \\
\hline & $\begin{array}{l}\text { Rate of villages who think they } \\
\text { should get higher education }\end{array}$ & $45.3 \%$ of the villagers & $79.5 \%$ of the villagers \\
\hline & $\begin{array}{l}\text { Rate of villages with technical } \\
\text { training and the training content }\end{array}$ & $\begin{array}{l}37.1 \% \text { villages offer agriculture } \\
\text { training }\end{array}$ & $\begin{array}{l}57.2 \% \text { villages offer both } \\
\text { agriculture training and } \\
\text { non-agriculture training }\end{array}$ \\
\hline \multirow[b]{2}{*}{ Medical } & $\begin{array}{l}\text { Rate of villages where there is } \\
\text { medical point }\end{array}$ & $25.1 \%$ villages & $79.2 \%$ villages \\
\hline & $\begin{array}{l}\text { The places for medicine and } \\
\text { medical treatment }\end{array}$ & $\begin{array}{l}\text { Medical point for minor illness } \\
\text { and village hospital for serious } \\
\text { illness }\end{array}$ & $\begin{array}{c}\text { Medical point for minor illness } \\
\text { and county hospital for serious } \\
\text { illness }\end{array}$ \\
\hline \multirow{4}{*}{$\begin{array}{l}\text { Infrastructure and } \\
\text { Public service }\end{array}$} & $\begin{array}{l}\text { Rate of villages where there are } \\
\text { water supply and sewerage pipes }\end{array}$ & $3.5 \%$ villages & $59 \%$ villages \\
\hline & Electric charge & $\begin{array}{l}\text { Per household annual electric } \\
\text { charge is } 100 \text { yuan }\end{array}$ & $\begin{array}{l}\text { Per household annual electric } \\
\text { charge is } 300 \text { yuan }\end{array}$ \\
\hline & Rate of villages where there is bus & $11 \%$ villages & $92 \%$ villages \\
\hline & $\begin{array}{l}\text { Rate of villages where there are } \\
\text { refuse disposal facilities }\end{array}$ & Nearly none & $51.2 \%$ villages \\
\hline
\end{tabular}

right; the other is the lands used by the government to resettle migrants in the city. Due to the increasingly tight land resources, resettlement in the city is more and more difficult.

\section{A Brief Plan for Allopatric Migration and Poverty Alleviation}

\subsection{Planning Guiding Ideology and Principle}

Guiding Ideology. Guided by the scientific outlook of development, in accordance with the overall requirements "being able to move out, live firmly, become rich", adhere to the working thought, "led by the government, voluntary principles, classification guidance, steady progress; policy support, market operation; open and fair, open operation", the government create a new way, "with migrant subsidies and financial poverty alleviation loans, the government activates folk dispersive funds", so as to promote the development of leading industry to revitalize the urban development and combine poverty alleviation with urbanization. The government should bring the implementation of migrant relocation and resettlement as the global and strategic work into the overall layout of the county's economic and social development. The government should combine the implementation of migrant relocation and resettlement with the development of county economy, encouraging farmers into the city, the construction of indemnificatory housing, the construction of industrial parks, and urban development, and then focus on solving the difficulty of farmers' children in attending school, the difficulty of farmers in seeking treatment and in revenue growth.

Fundamental Principles. Nearby relocation principle, the principle of acting according to capability; the principle of combining construction of new migrant villages with combination small villages and large villages; the principle of combining government guidance with resources of the masses; the principle of combining bene- 
fits and long-term interests.

\subsection{Planning Scope and Duration}

2230 persons from 567 families of Dongguan Village and Xiguan Village in Xinshui Village, will be moved to Nanguan Village in the Planning from 2016 to 2018.

\subsection{Goals and Important Mission}

\subsubsection{The Overall Goals}

The overall goals including 567 sets of farmers' residence in 34950 square meters; water supply pipeline of 3500 meters in village; rural power lines of 3500 meters; Roadway sclerosis of 7000 square meters; green area of 4500 square meters and other subsidiary facilities with 10000 square meters. Moreover, every 1 to 2 person will master at least one practical technology and all school-age children will go to school. Economic income and living standard of immigrants will reach the average level of local resettled residents and farmers.

\subsubsection{Major Missions}

Program Planning

(1) Immigrant Condition and Scale. There are 567 immigration households identified by filing the census register, which accounts for $97.8 \%$ of resident population in the original village.

(2) Immigrant Way. The whole village relocation and the collective resettlement mode will be made under the government's guidance, local enterprises' participation and farmers' voluntary.

(3) Allowances. The first is "per capita-the total price". For the per capita area of 15 square meter with the charge of 2001 yuan/square meter, each household can only purchase subsidies (housing) according to number of family members. They will get the government subsidies by $70 \%$ if the total price is within 100,000 yuan, and the government subsidies by $60 \%$ if the total price is more than 100,000 yuan. Second is "homestead + population". If the whole family member is less than three, the ratio of dismantling \& settling building and the previous land area is $5: 3$. If the whole family member is more than three, the ratio of dismantling \& settling building and the previous land area is 5:4.

Area Planning

(1) Economic Area. Featured agriculture, green industry and the cultural brand of the third industry should be developed. Industrial structure should be optimized to achieve rational utilization of resource and build advanced production and marketing links. For example, according to the geologic characteristics, Xiguan Village could build gardens of kinds of fruit trees and develop sightseeing agriculture and tourism while Dongguan Village could develop the local watermelon producing and processing industry.

(2) Social Area. Infrastructure constructions for basic living conditions such as road, water supply, water draining and power supply should be improved. Enlarging school scale and consummating medical condition in Nanguan Village, the introduction of high-quality talent in education and health care should be done.

(3) Ecological Area. Ecologic restoration and improvement the original area should be proceeded. And drainage and greening work in the new community should be enhanced to make it a beautiful and livable demonstration village.

Policy Planning

(1) Financial preferential policies. Innovation of rural financial system reform, exploration of the "three rights" (Resident building property right, Forest right and Estates of contracted land) mortgage business should be developed. It will help immigrants to get venture projects and enjoy the small-sum guaranteed loan less than 50000 yuan, as well as preferential policies and "three rights" mortgage loan provided by department of labor and employment.

(2) Poor families with special card ID policy. To make sure the accuracy of poverty alleviation and smooth implementation of disaster relief, investigation and registration of the poor families should be done so that every family has a special card ID for identification.

(3) Carbon sequestration and environmental policy. This policy is supposed to put into practice. The amount of carbon emission and absorption should be equal. For example, you have to plant three trees in the country if you want to buy a car or plant one tree if you buy a motorcycle. Planting trees is equivalent to paying for their carbon emission. 


\section{Acknowledgements}

Fund Project: the National Social Science Fund "The reconstruction research of the household living of the eco-migration on Loess Plateau based on the national perspective” (No.15BMZ094).

\section{References}

[1] The State Council Leading Group Office of Poverty Alleviation and Development. "2001-2010 Poverty Alleviation and Development Outline in China Rural Area” Mid-Term Evaluation Policy Report. 2005.

[2] Zhang, R. (2016) Studying Within-Village Poverty Alleviation Immigrant Model in Shanxi and Shaanxi Provinces. Shanxi Normal University, Linfen.

[3] (1990) Compilation Committee of the History of Daning County. The History of Daning County. Haichao Press, 57.

[4] Sun, M.L. (2008) The Benefit Evaluation of Ecological Immigrant Project in Jingbian Province. Shaanxi Normal University, Linfen.

[5] Wang, Y.B. (2011) The Benefit of Ecological Migrant Project Evaluation and Degree of Satisfaction Analysis in Inner Mongolia. Beijing Forestry University, Beijing.

[6] Shanxi Province People's Government (2012) Notification on Issuance of Relieving People in Shanxi Province by Giving Them Employment Instead of Outright Grant and Ex-Situ Anti-Poverty Removal in the "12th Five-Year Plan” by General Office of Shanxi Province People’s Government. Shanxi Political Newspaper, No. 22, 11-28. 